\title{
Implementation of School Information Systems Using the CodeIgniter Framework
}

\section{Penerapan Sistem Informasi Sekolah Menggunaka Framework CodeIgnter}

\author{
${ }^{1}$ Muhamad Zuhan Aminurrohman, ${ }^{2}$ Arizona Firdonsyah \\ \{muhammadzuhan19@gmail.com ${ }^{1}$, arizona@unisayogya.ac.id ${ }^{2}$ \}
}

Program Studi Teknologi Informasi, Fakultas Sains dan Teknologi, Universitas ‘Aisyiyah, Yogyakarta, Jl. Siliwangi (Ring Road Barat) No. 63, Yogyakarta, Indonesia

\begin{abstract}
The development of Information and Communication Technology is growing rapidly. The need to obtain information quickly and easily encourages people to create better information and communication technologies. The development of this technology has affected all sectors, including in the world of education. Education in Indonesia shows a low quality because some schools still do not take advantage of technological developments. Therefore, schools in Indonesia must start updating school management to create efficient and more advanced management, including the use of the school information system. School Information System is an information system that helps in managing school information. The method used is a literal study by looking at and comparing existing research. The expected result of this research is a website-based school information system.
\end{abstract}

Keywords - Information Technology, School Information Systems, CodeIgniter

\begin{abstract}
Abstrak. Perkembanngan Teknologi Informasi dan Komunikasi tumbuh dengan pesatnya. Kebutuhan memperoleh informasi secara cepat dan mudah mendorong manusia untuk menciptakan teknologi informasi dan komunikasi yang lebih baik. Perkembangan teknologi ini seluruh sektor mendapatkan imbas nya termasuk dalam dunia pendidikan. Pendidikan di Indonesia menunjukkan kualitas yangmasih rendah diseabakan oleh beberapa sekolah masih belum memanfaaatkan perkembangan teknologi. Oleh karena itu sekolah-sekolah di Indonesia harus mulai memperbaharui manajemen sekolah untuk menciptakan pengelolaan yang efisian dan lebih maju, termasuk didalamnya penggunaan system inforamsi sekolah. Sistem Informasi Sekolah merupakan system informasi yang membantu dalam mengelola informasi sekolah. Metode yang digunakan adalah studi literais dengan melihat dan membandingan penelitian yang sudah ada. Hasil yang diharapakan dari penelitian ini adalah sebuah system informasi sekolah berbasis website.
\end{abstract}

Kata Kunci - Teknologi Informasi, Sistem Informasi Sekolah, CodeIgnter

\section{Pendahuluan}

Perkembanngan Teknologi Informasi dan Komunikasi berkembang dengan pesat. Kebutuhan memperoleh informasi secara cepat dan mudah mendorong manusia untuk menciptakan teknologi informasi dan komunikasi yang lebih baik[1].

Teknologi Informasi dan Komunikasi (TIK) memuat tiga kata, yaitu teknologi, informasi, dan komunikasi yang masing-masing memiliki definisi. Teknologi adalah pengembangan dan pengaplikasian yang bertujuan untuk memecahkan masalah. Sehingga, teknologi disebut dengan penemuan-penemuan baru yang bersifat membantu. Informasi adalah hasil pemrosesan data untuk tujuan dan manfaat tertentu. Komunikasi adalah proses penyampaian informasi dari pemberi informasi kepada penerima informasi. Sehingga, informasi dan komunikasi ini sangatlah erat kaitannya[2].

Perkembangan teknologi memberikan dampak terhadapan sektor-sektor di Indonesia termasuk di sektor pendidikan. Pendidikan sebagai salah satu bagian yang tidak terpisahkan dari proses pendewasaan manusia tentu di satu sisi memiliki andil yang besar bagi pengembangan ilmu pengetahuan dan teknologi, oleh karena itu pendidikan memanfaatkan kemajuan ilmu pengetahuan dan teknologi agar mencapai tujuannya secara efektif dan efisien[3].

Pendidikan di Indonesia menunjukkan kualitas yang rendah. Karena pemerintah kurang memperhatikan bidang pendidikan. Kemajuan bangsa Indonesia salah satu yang terpenting adalah pendidikan, karena pendidikan merupakan modal dasar untuk kemajuan suatu bangsa. Kesenjangan dalam pendidikan di Indonesia masih terjadi seperti sarana prasarana, sumber daya tenaga pendidikan[4].

Keberadaan teknologi informasi bagi dunia pendidikan berarti tersedianya saluran atau sarana yang dapat dipakai untuk menyiarkan program pembelajaran baik secara searah maupun secara interaktif[5]. Menyampaikan program pembelajaran dengan metode yang baru dengan menggunakan keberadaan teknologi informasi dapat memberikan suasana yang baru dan mencipatakan pembelajaran yang aktif. Dengan hal itu, suasana pembalajaran dapat memberikan kenyamanan dan keasikan dalam media pembelajran. 
Perkembangan teknologi informasi juga diharapkan dapat membawa bidang pendidikan menuju peningkatan kualitas dan mekanisme pelayanan pelayanan di bidang pendidikan agar lebih berdaya guna dan berhasil guna[6]. Dilihat dari beberapa sekolah aynag ada di indoensia masih banyak sekolah yang masih kurang dalam memanfaatkan perkeembangan teknologi informasi. Pelayanan-pelayanan yang ada di sekolah juga semestinya mendapatkan pembaharuan dalam meningkatkan kepercayaan orang tua terhadap sekolah. Meningkatkan kualitas pendidikan di Indonesia dengan membuat sistem informasi sekolah mempunyai peran yang penting.

System informasi merupakan suatu system didalam suatu organisasi yang mempertemukan kebutuhan pengolahan transaksi harian, mendukung operasi, bersifat manjerial dan kegiatan startegi dari suaatu organisasi dan menyediakan pihak luar tertentu dengan laporan-laporan diperlukan[7]. System informasi sekolah berarti kumpulan komponen didalam lingkup sekolah yang berfungsi sebagai pengolahan untuk menghasilkan sebuah laporan-laporan yang disajikan kepada pihak tertentu, seperti laporan sekolah.

Sistem informasi sekolah memberikan manfaat yang banyak bagi sekolah, guru, siswa, dan juga orang tua/wali. Sistem informasi sekolah berkerja dengan mengelola data-data sekolah, data sekolah bisa di bilang data yang komplek dalam dunia pendidikan. Dari laporan peserta didik baru, hingga sampe pelaporan hasil peniliain selama 3 tahun. Murid, guru, wali, siswa, bangunan sekolah pun mempunyai data-data yang penting. Termasuk laporan-laporan yang harus dilihat atau di publiskan kepada masyarakat.

Memanajemen data sekolah memerlukan sebuah system yang dapat membantu mengelola, menyimpan, dan mengolah data sekolah. Sehingga system informasi sekolah ini dapat memberikan kemudahan kepada pihak sekolah dalam menciptakan sekolah yang modern.

Pada sistem informasi sekolah ini akan digambarkan aliran data yang dimulai dari proses pendaftaran siswa untuk test, proses penentuan siswa yang lulus test, pendaftaran ulang siswa baru, pembagian kelas, kehadiran siswa, nilai siswa, laporan siswa yang lulus test dan diterima, raport siswa dan laporan siswa perkelas [8].

System informasi sekolah berbasis web juga memudahkan wali murid dalam memantau anaknya bahkan hingga mengecek keuangan dalam akses yang lebih mudah. Namun era sekarang pun masih banyak sekolah sekolah yang masih memberikan informasi penting dengan harus mengundang mengumpulkan wali muridnya ke sekeloh. Ini membuat beberapa wali murit tidak dapat menghadiri undangan tersebut maka informasi yang penting pun tidak tersampaikan kepada orang tua. Dengan hal itu dibuatnya aplikasi system informasi sekolah dapat menguntungkan seluruh pihak yang terkait dalam lingkup sekolah.

Pembuatan system informasi sekolah akan menggunakan framework codeignter. Framework adalah kumpulan intruksi-intruksi yang di kumpulkan dalam class dan function-function dengan masing-masing untuk memduahkan developer dalam memanggilnya tanpa harus menuliskan syntax program yang sama berulang0ulang serta dapat menghemat waktu. CodeIgniter merupakan framework PHP yang dibuat berdasarkan model view Controlleer (MVC). Konsep MVC memberikan pemisahan antara layer application=logic dan presentation. Penggunaan konsep ini kode PHP, query, Mysql, Javascript dan CSS dapat saling dipisah-pisahkan sehingga ukuran file menjad lebih kecil dan lebih mudah dalam maintenance.

CI memiliki library yang lengkap untuk mengerjakan operasi-operasi yang umum dibutuhkan oleh aplikasi berbasis web misalnya mengakses database, memvalidasi form sehingga sistem yang dikembangkan mudah. CI juga menjadi satu-satunya Framework dengan dokumentasi yang lengkap dan jelas. Source code CI yang dilengkapi dengan comment didalamnya sehingga lebih memperjelas fungsi sebuah kode program dan CI yang dihasilkan sangat Bersih (clean) dan search Engine Friendly (SEF). Codeigniter juga dapat memudahkan developer dalam membuat aplikasi web berbasis PHP, karena framework sudah memiliki kerangka kerja sehingga tidak perlu menulis semua kode program dari awal[7]. Hal itu yang mendasari penilitian ini menggunakan framework CodeIgnter dalam pembuatan Sistem Informasi Sekolah.

Penelitian yang mendekati dan serupa ini berjudul "Rekayasa Sistem Informasi Akademik Sekolah Berdasarkan Kurikulum 2013 dengan Menggunakan Framework Codeignter”, dengan peneliti Jihan Ali Ahmad, Universitas Negeri Semarang, tahun 2014 dan penelitian yang serupa ini berjudul "Analisa dan Perancangan Sistem Informasi Sekolah Berbasis Website Untuk Penyampaian Informasi Sekolah dan Media Promosi Kepada Masyrakat", dengan peneliti Yudie Irwan, dkk, dari Universitas Muria Kudus, tahun 2016. Perbedaan penelitian dari kedua penelitian tersebut yaitu system yang dibuat dan framework yang digunakan[1][9].

\section{METODE}

\section{A. Studi Literatur}

Studi literatur merupakan studi perbandingan dengan membandingkan penelitian yang mendekati atau serupa dari penelitian sebelumnya dengan mencari data-data dari buku, jurnal atau artikel yang ada di perpustakaan dan internet. Data-data yang yang terdapat di buku maupun internet, yang dijadikan referensi 
Procedia of Engineering and Life Science Vol. 1. No. 2 Juni 2021

Seminar Nasional \& Call Paper Fakultas Sains dan Teknologi (SENASAINS $2^{\text {nd }}$ )

Universitas Muhammadiyah Sidoarjo

yaitu yang berkaitan dengan sistem informasi sekolah, meningkatakan mutu sekolah dan perkembangan teknologi yang digunakan di pendidikan 


\section{B. Kuesioner}

Metode pengumpulan data dengan menggunakan kuesioner online yang akan diberikan kepada responden, yaitu dengan memberikan pertanyaan-pertanyaan yang berkaitan dengan sistem informasi sekolah.

C. Observasi

Metode pengumpulan data dilakukan dengan cara pengamatan di sekolah pada bagian-bagian yang berada di sekolah dengan maksud untuk mendapatkan data dan dokumen secara langsung yang benar-benar terjadi pelaksanaan atau proyek.

\section{HASIL DAN PEMBahasan}

\section{A. Hasil Analisa Kebutuhan Sistem}

Analisis kebutuhan sistem dilakkan berdasarkan hasil sistem yang berjalan, Diperoleh hasil analisis sebagai berikut:

1. Guru mata pelajaran mengelola nilai akademik dengan menggunakan Ms. Excel, sehingga guru mata pelajaran harus teliti dalam menulis data siswa.

2. Guru wali kelas harus mencatat kembali dari hasil data nilai yang sudah di simpan oleh guru mata pelajaran untuk menghitung dan mencetak raport nilai siswa.

3. Siswa tidak bisa melihat hasil belajarnya secara berkala, sehingga penilaian oleh guru dianggap kurang transparan.

4. Data nilai yang tersimpan belum terbackup kedalam database, sehinggga rekap data nilai siswa dari alumni tidka bisa diakses.

5. Informasi mengenai sekolah masih dianggap kurang terpublik, sehingga informasi terkait pendafataran hingga pembiyaan masih harus mendatangi ke sekolah.

6. Kegiatan sekolah yang kurang ditangani dengan baik, sehingga sebagai ajang promosi sekolah masih kurang.

B. Hasil Desain

Desain Perangkat Lunak menggunakan 4 diagram UML.

1. Use case diagram. Use case diagram menyatakan visualisasi interkasi yang terjadi antara pengguna (aktor) dengan system. Actor adalah segala sesuatu yang berinterkasi dengan sistem[10]. Use casse diagaram dibua untuk

- Use case diagram administrator

- Use case diagram Guru Mata pelajaran

- Use case diagram Guru Wali Kelas

- Use case diagram siswa

2. Activity Diagram digunakan untuk menjelasakan proses Use case yang berjalan dari satu aktifitas ke aktifitas yang lain. Activity diagram yang akan dibuat diantaranya:

- Activity diagram input informasi sekolah

- Activity diagram input data guru

- Activity diagram input data siswa

- Activity diagram input nilai siswa

- Activity diagram input nilai rapot

- Activity diagram input data tagihan keuangan

- Activity diagram input data penilaian guru

3. Class Diagram menjelaskan kelas-kelas objek yang ada pada system yang saling berhubungan dengan kelas-kelas objek yang lain. Class diagram mendeskripsikan jenis-jenis obejek dalam system dan berbagai macam hubungan interaksi diantara objek tersebut.

4. Statechart Diagram perangkat lunak system informasi sekolah menjelaskan siklus kerja berdasarkan tingkah laku suatu objek sampai objek dieksekusi.

C. Hasil Interface

Hasil interfacenya diharapkan dibuat secara praktis dan mudah di paham.

1. Halaman Utama Sistem Informasi Sekolah 
Halaman utama Sistem Informasi Sekolah berisikan artikel-artikel atau berita seputar kegaiatan sekolah.Halaman utama akan menampilkan desain yang mudah di paham dan menarik. Halam utama juag menjadi bahan promosi untuk sekolah. Oleh karena itu halaman utama menampilkan informasi sekolah, seperti jumlah siswa saat ini, dan masih banyak lagi. Seluruh kegiatan Dan halaman utama terdapat beberapa menu home dan login.

2. Halaman User Admin

Halaman user admin yang mempunyai beberaoa menu, serta menu yang merekap seluruh data yang ada di system

3. Halaman utama Guru Mata Pelajaran

Halaman yang mempunyai menu kegiatan pembelajaran, dari mengelola nilai tugas pelajar yang diampu sampai nilai perilaku siswa. Serta terdapat menu jadwal mengajar

4. Halaman utama Siswa

Halaman utama siswa memiliki beberapa menu utama seperti jadwal pelajar, dan nilai-nilai Ujian/Tugas

\section{KESIMPULAN}

Kesimpulan dari penilitian ini adalah memberikan sebuah solusi berupa sistem informasi sekolah dalam memudahkan dalam menejemen sekolah, sehingga sistem yang berjalan di sekolah juga mendatkan pembaharuan demi meniningkatkan pelayanan yang ada di sekolah. Oleh karena itu sistem ini memberikan pengaruh terhadap kemajuan dan kondisi sekolah.

\section{REFERENSI}

[1] J. A. Ahmad, "Rekayasa Sistem Informasi Akademik Sekolah Berdasarkan Kurikulum 2013 Dengan Menggunakan Framework Codeigniter,” Edu Komputika J., vol. 1, no. 1, pp. 22-33, 2014, doi: 10.15294/edukomputika.v1i1.4120.

[2] I. Huda, "Research \& Learning in Primary Education Perkembangan Teknologi Informasi dan Komunikasi ( TIK ) Terhadap Kulaitas Pembelajaran Di Sekolah Dasar," Asmar, vol. 2, no. 1, pp. 121-125, 2020.

[3] A. Muhson, "Pengembangan Media Pembelajaran Berbasis Teknologi Informasi," J. Pendidik. Akunt. Indones., vol. 8, no. 2, 2010, doi: 10.21831/jpai.v8i2.949.

[4] E. Nasution, "Problematika Pendidikan di Indonesia Oleh :," urnal Fak. Ushuluddin Dan Dakwah IAIN Ambon, pp. 1-10, 2008.

[5] farhania putri yusril, "PEMANFAATAN TEKNOLOGI INFORMASI DALAM BIDANG PENDIDIKAN (E-education)," vol. 2, no. 1, 2019, doi: 10.31219/osf.io/ycfa2.

[6] D. J. Kuss, M. D. Griffiths, J. F. Binder, and B. Street, "Metadata, citation and similar papers at core.ac.uk," pp. 1-19, 2013.

[7] M. Destiningrum and Q. J. Adrian, "Sistem Informasi Penjadwalan Dokter Berbassis Web Dengan Menggunakan Framework Codeigniter (Studi Kasus: Rumah Sakit Yukum Medical Centre),” J. Teknoinfo, vol. 11, no. 2, p. 30, 2017, doi: 10.33365/jti.v11i2.24.

[8] R. 2014 Afyenni, "Perancangan Data Flow Diagram untuk Sistem Informasi Sekolah (Studi Kasus Pada SMA Pembangunan Laboratorium UNP)," Teknoif, vol. 2, no. 1, pp. 35-39, 2014.

[9] Y. Irawan, N. Susanti, and W. A. Triyanto, "Analisa Dan Perancangan Sistem Informasi Sekolah Berbasis Website Untuk Penyampaian Informasi Sekolah Dan Media Promosi Kepada Masyarakat,” Simetris J. Tek. Mesin, Elektro dan Ilmu Komput., vol. 7, no. 1, p. 257, 2016, doi: 10.24176/simet.v7i1.512.

[10] T. A. Kurniawan, "Pemodelan Use Case (UML): Evaluasi Terhadap beberapa Kesalahan dalam Praktik," J. Teknol. Inf. dan Ilmu Komput., vol. 5, no. 1, p. 77, 2018, doi: 10.25126/jtiik.201851610. 